\title{
Projeto gráfico-editorial de livros didáticos de Língua Portuguesa: definição, tensões e possibilidades
}

\author{
Fabiana Panhosi Marsaro \\ Universidade Estadual de Campinas
}

\begin{abstract}
Resumo
Neste artigo pretendemos discutir a importância do projeto gráfico-editorial para a produção e utilização de livros didáticos de Língua Portuguesa, procurando definir esse objeto, discutir suas condições de produção e sua relevância na produção de livros didáticos adequados às demandas linguísticas atuais, considerados os letramentos complexos exigidos pela sociedade contemporânea. Para tanto, nos valeremos de uma exposição teórica e também da análise de dois exemplos de atividades de leitura em um livro didático cujo projeto gráfico-editorial inadequado teve influências negativas no seu projeto pedagógico.

Palavras-chave: Livro didático, projeto gráfico-editorial, leitura, letramentos
\end{abstract}

\begin{abstract}
This article discusses the importance of graphic-editorial projects for the production and use of Portuguese language textbooks. The article attempts to define this kind of project and explore the conditions of its production and its relevance in the mass production of appropriate textbooks for current linguistic needs, taking into consideration the complex literacies that contemporary society demands. A review of theory is given, and two examples of reading activities in a textbook are analyzed, showing negative effects on the pedagogical project owing to an inadequate graphic-editorial project.
\end{abstract}

Keywords: Textbooks, graphic-editorial project, reading, literacies

\section{INTRODUÇÃO}

Choppin (2004), em seu panorama da história dos livros e das edições didáticas, define duas grandes categorias de pesquisa envolvendo o livro didático (doravante LD). Segundo o autor, na primeira categoria estão as pesquisas que "concebendo o livro didático apenas como um documento histórico igual a qualquer outro, analisam os conteúdos em uma busca de informações estranhas a ele mesmo (...) ou as que só se interessam pelo conteúdo ensinado por meio do livro didático" (2004, p. 554, grifo nosso). Na segunda categoria, concentram-se aquelas que, "negligenciando os conteúdos dos quais o livro didático é portador" (Choppin, 2004, p. 554), o encaram como um objeto físico, um produto fabricado, comercializado e distribuído com usos 
específicos e avaliado a fim de atender as demandas de um contexto determinado (Choppin, 2004, p. 554, grifo nosso).

Ainda que o autor ressalte que "essa distinção é seguramente esquemática, uma vez que uma pesquisa geralmente participa - ainda que em proporções variáveis — das duas categorias" (Choppin, 2004, p. 554), notamos que, de fato, é possível observar uma divisão entre os estudos que se voltam para os conteúdos do LD - geralmente nas áreas de Letras, Pedagogia e História - , e aqueles que se dedicam a analisar seus aspectos formais, sempre em menor proporção - no Design Gráfico e Editoração, por exemplo - poucas vezes buscando compreender suas interrelações.

Ilustrando essa constatação, podemos trazer a citação de Moraes (2010), que destaca o exemplo significativo do Simpósio Internacional do Livro Didático Educação e História, realizado em 2007, em São Paulo, no qual,

dos 176 artigos apresentados em suas comunicações e constantes no caderno de resumos, apenas um trata diretamente de aspectos da configuração visual do livro didático e quatro versam sobre iconografia encontrada principalmente em livros de História (Moraes, 2010, p. 23).

Ainda sobre esse panorama, podemos voltar mais uma vez a Choppin (2004), que o justifica de maneira bastante pertinente:

Por razões que dizem respeito à formação de pesquisadores e à carência de instrumentos apropriados, as análises dos livros didáticos, independentemente de suas problemáticas, ficam tradicionalmente restritas — ao menos no Ocidente — à análise de texto. (...) Têm sido negligenciadas as características "formais" dos livros didáticos. A organização interna dos livros e sua divisão em partes, capítulos, parágrafos, as diferenciações tipográficas (fonte, corpo de texto, grifos, tipo de papel, bordas, cores, etc.) e suas variações, a distribuição e a disposição espacial dos diversos elementos textuais ou icônicos no interior de uma página (ou de uma página dupla) ou de um livro só foram objeto, segundo uma perspectiva histórica, de bem poucos estudos, apesar dessas configurações serem bastante específicas do livro didático. Com efeito, a tipografia e a paginação fazem parte do discurso didático de um livro usado em sala de aula tanto quanto o texto ou as ilustrações (Choppin, 2004, p. 559, grifos nossos).

Acrescentamos às considerações do autor a ideia de que essa lacuna formada entre os diferentes enfoques no estudo e entendimento desse tipo de material pode ser reflexo da configuração atual do LDP que é, simultaneamente, instrumento de ensinoaprendizagem e produto do mercado editorial, como tentaremos mostrar.

Neste artigo, portanto, levando em conta a pouca atenção dada pelas pesquisas aos aspectos formais do LD, procuraremos discutir o projeto gráfico editorial de livros 
didáticos de língua portuguesa, entendendo que elementos como tipografia, espaços em branco, uso de cores, escolha de imagens, entre tantos outros, participam do processo pedagógico tanto quanto o texto autoral e a coletânea. Para tanto, apresentaremos uma definição para o projeto gráfico-editorial, discutiremos as tensões existentes na sua produção e faremos uma tentativa de aproximar esse objeto à discussão dos letramentos complexos exigidos pela sociedade contemporânea, finalizando com a análise de alguns exemplos.

\section{PROJETO GRÁFICO-EDITORIAL: UMA DEFINIÇÃO}

Na busca por uma definição, podemos dizer que o projeto gráfico-editorial de um livro didático de língua portuguesa (que passaremos a chamar LDP) compreende o planejamento - editorial - e a realização - gráfica - da sua forma, conteúdo e composição. Coordenado pelo editor e executado por ele e por outros agentes sob sua responsabilidade, como designers, ilustradores, diagramadores e copidesques, o projeto gráfico-editorial resulta na configuração visual do LDP e também no seu conteúdo final, preparado, revisado e alterado a partir dos originais do autor. Segundo Collaro, a diagramação de um livro "consiste em aliar todo conhecimento estético e técnico ao custo" (Collaro, 1987, p. 45), o que faz com que as escolhas realizadas pelo editor tenham que ser compatíveis com o orçamento previsto para o LDP. O controle de custos de copyright, por exemplo, tem uma grande influência na produção de coleções e na seleção da coletânea. Os direitos autorais para a reprodução de obras de arte e a inserção de tirinhas e charges têm um custo elevado, por exemplo, o que pode explicar o uso recorrente de ilustrações editoriais, encomendadas especialmente para aplicação no livro didático.

Nos termos de Chartier (1999), o projeto gráfico corresponde à mise en livre ou aos procedimentos da colocação em livro. Segundo o autor,

os procedimentos de colocar em livro [...] podem apropriar-se diferentemente do mesmo texto. Eles variam historicamente e também em função de projetos editoriais que visam usos ou leituras diferentes (Chartier, 1999, p. 251).

Quanto às variações históricas a que se refere o autor, podemos constatar que as evoluções tecnológicas reduziram consideravelmente os custos e a dificuldade em organizar um material, imprimi-lo e distribuí-lo em grandes quantidades. 
Com o aparecimento de plataformas operacionais como os sistemas Macintosh (introduzido pela Apple em 1984) e Windows (introduzido pela Microsoft para concorrer com o primeiro), tornou-se não somente possível como simples e barato manipular fontes, espacejamento, entrelinhamento e uma série de outros elementos gráficos que antes eram de domínio quase exclusivo do tipógrafo profissional. (Denis citado por Pivetti, 2005, p. 6).

Também podemos dizer que a nova configuração da nossa sociedade, altamente tecnológica, tem influenciado os projetos gráfico-editoriais de diversos materiais. $\mathrm{O}$ uso maciço da Internet e de várias outras mídias possibilita uma relação dinâmica e instantânea com a informação e com as imagens. Nesse contexto, entende-se que os materiais impressos, para continuarem atrativos e rentáveis, devem acompanhar essa interatividade. Essa necessidade de atualização constante é pertinente também ao LDP, uma vez que, como podemos constatar, muitas vezes obras são reeditadas ou relançadas sem grandes alterações no conteúdo e o fator novidade fica por conta do visual: ilustrações diferentes ou uma nova capa, por exemplo.

É interessante observar, porém, que ainda que os avanços tecnológicos façam com que a maioria dos processos que envolvem a execução do projeto gráfico-editorial sejam eletrônicos, ele exige escolhas conscientes por parte de seus realizadores, ou seja, a intervenção de pessoas com ideologias e apreciações de valor específicas.

\footnotetext{
Por meio da editoração eletrônica, o designer gráfico tem a possibilidade de tornarse um 'artista-artesão', a partir do momento em que o projeto gráfico de um livro pode desenvolver-se num processo que permite ser acompanhado do início ao fim, artisticamente, pela mesma pessoa, a qual tem autonomia técnica para intervir e corrigir pessoalmente o trabalho, a qualquer hora (Pivetti, 2005, p. 9).
}

Entendido o LDP como um gênero secundário do discurso, podemos dizer que o projeto gráfico-editorial determina "a ordem, a disposição, o acabamento, a combinação das massas verbais" (Bakhtin, 2003 [1952-53/1979], p. 211), ou seja, que diz respeito à forma de composição do gênero. Imbricada ao estilo e aos temas, a forma de composição do LDP é bastante específica desse tipo de material. Uma vez que "o enunciado, seu estilo e sua composição são determinados pelo objeto do sentido e pela expressividade, ou seja, pela relação valorativa que o locutor estabelece com o enunciado" (Bakhtin, 2003 [1952-53/1979], p. 316), é através do projeto gráficoeditorial, também, que editor, autor e outros agentes, em maior ou menor proporção, assinalam seus pontos de vista sobre os objetos de ensino. Ressaltamos que os 
procedimentos e as características do projeto gráfico-editorial resultam também de um contexto de coautoria, próprio do LDP, que discutiremos brevemente a seguir.

\section{PROJETO GRÁFICO-EDITORIAL E A COAUTORIA DO LIVRO DIDÁTICO}

A Teoria Bakhtiniana nos permite entender a autoria como uma categoria sociodiscursiva, "onde a dimensão textual e a dimensão social se encontram e se coconstituem" (Alves Filho, 2006, p. 78). Segundo Faraco, reformulando a definição de Bakhtin, "a função estético-formal de autor-criador é [...] uma posição axiológica" que, por sua vez, "é um modo de ver o mundo, um princípio ativo de ver que guia a construção do objeto estético e direciona o olhar do leitor" (2005, p. 41-42). Dessa forma, o autor pode ser definido como um organizador daquilo que acontece no mundo, caracterizado não necessariamente pela invenção de algo novo, mas pela maneira singular como organiza, segundo sua ideologia, a linguagem o e os acontecimentos da vida.

Nessa perspectiva, para produzir um LDP, o autor assume uma postura ideológica que acaba por definir a proposta pedagógica da obra. A partir dos Parâmetros Curriculares Nacionais e de outros referenciais, ele seleciona objetos de ensino e define a maneira como vai ensiná-los, lidando com diversas vozes, que, entendidas conforme o conceito de Bakhtin (1988 [1934-35/1975]), são diversos pontos de vista sobre o mundo, isto é, diferentes ideologias interpretadas verbalmente, seja na linha teórica adotada, nos textos da coletânea ou nos tipos de exercício propostos. Ao reorganizar essas vozes diversas, fazendo com que, no produto final, a ideologia predominante seja a sua e, consequentemente, da sua visão e proposta pedagógica para o ensinoaprendizagem da Língua Portuguesa, o autor dá ao LDP o acabamento estético que é próprio de sua função.

Como argumenta Bragança, porém, "todos os livros são produto da ação combinada do autor e do editor. Às vezes gestados mais pelo autor, outras vezes criados pelo editor" (2005, p. 222). Os trabalhos de Roger Chartier (1945/1999, 1981/2001) mostram que, na história do livro de maneira geral, a figura do editor, longe de ser neutra, aparece sempre em tensão com a do autor, uma vez que, segundo ele, "um processo de leitura [pode ser] ajudado ou derrotado pelas próprias formas dos materiais que lhe é dado ler" (Chartier, 2001, p. 96). Podemos dizer que 
durante todo o processo que envolve a produção de livros didáticos, passando pela preparação do original, revisão, apreciação de um parecerista, contato com o autor, com o departamento de arte, acerto dos direitos autorais, diagramação entre outras etapas, até o envio do arquivo final para a gráfica, o editor tradicional desempenha a sua participação exercendo certo controle sobre essa produção (Tenan et al., 2008, p. 7).

Segundo Bragança (2005, p. 224), esse controle do editor no processo de criação de uma obra começa no fato de que a existência de um livro depende, antes de tudo, da sua decisão de publicar ou não um original, decisão essa tomada a partir de critérios e motivações que podem não ser as mesmas do autor.

\begin{abstract}
São os editores [...] que decidem que textos vão ser transformados em livros. E, pensando em qual público a que devem servir, como serão feitos esses livros. Mesmo quando não é deles a iniciativa dos projetos, é deles que parte a direção a seguir. É neste lugar de decisão e de comando, e de criação, que está o coração do trabalho de editor. É também esse lugar que exige dele saberes específicos ("escolher, fabricar, distribuir"), que o diferenciam dos demais agentes envolvidos no processo editorial, e lhe impõe responsabilidades únicas, profissionais, sociais, econômicas, financeiras, administrativas e mesmo (juntamente com os autores) judiciais (Bragança, 2005, p. 224).
\end{abstract}

Considerando que na dinâmica editorial o autor e o editor são os agentes mais relevantes, podemos entender o processo de produção de um LDP também como um processo de negociação entre autores e editores: "os autores e editores de LDP selecionam/negociam determinados objetos de ensino e elaboram um livro didático, com capítulos e/ou unidades didáticas, para ensiná-los" (Rojo \& Bunzen, 2005, p. 16). Nessa criação negociada, "quem confere um acabamento aos textos e faz as escolhas estilísticas são os autores, embora inseridos sempre em conformações ideológicodiscursivas" (Alves Filho, 2006, p. 78), porém, sejam movidos por interesses mercadológicos ou mesmo pedagógicos, os editores acabam tendo influência direta na estrutura composicional dos LDP e, consequentemente, no seu acabamento e estilo.

Considerando o perfil determinado para a coleção, seu público-alvo, ou mesmo questões de ordem mais prática, como custos de copyright e impressão, o editor pode intervir na seleção dos textos da coletânea, na escolha de imagens e ilustrações, reorganizando a orquestração autoral anterior do LD e, por vezes, comprimindo a proposta pedagógica do autor em um projeto gráfico-editorial não condizente, o que coloca em xeque a relação entre as exigências do mercado editorial e os propósitos do ensino-aprendizagem. 
No contexto brasileiro, podemos apontar um outro fator determinante na produção e caracterização dos LPD e, consequentemente, de seus projetos gráficoeditoriais: o Programa Nacional do Livro Didático - PNLD ${ }^{1}$.

\section{PROJETO GRÁFICO-EDITORIAL E O PNLD}

Instituído pelo Ministério da Educação em 1985, com o objetivo de forçar melhorias na qualidade dos LD, o PNLD trouxe consigo as avaliações. Desde 1996, como parte desse processo de avaliação, o PNLD publica trienalmente o "Guia Nacional do Livro Didático", com resenhas das coleções recomendadas para escolha pelas escolas. O Guia, por sua vez, é precedido por um "Edital de Convocação”, que contém as especificações técnicas mínimas para a inclusão das coleções no Programa. Nesses dois documentos, encontramos os critérios que norteiam a avaliação dos LDP e que abarcam, como esperado, o projeto gráfico-editorial.

No Edital do PNLD podemos encontrar a descrição dos critérios de triagem das coleções pelo IPT - Instituto de Pesquisas Tecnológicas, vinculado à Secretaria de Desenvolvimento do Estado de São Paulo, responsável por realizar o que seria o controle de qualidade dos LDP, vistos, nessa etapa, essencialmente como produtos. As especificações do Edital, em sua maioria, têm o intuito de estabelecer um padrão de produção do LDP e de zelar por sua segurança, tal qual é feito com outros tipos de bens consumíveis. Liberadas na análise do IPT, as coleções estariam, então, aprovadas quanto às especificações técnicas, podendo passar para a etapa seguinte da avaliação, que corresponde aos critérios divulgados no Guia do PNLD.

No Guia do PNLD/2008 - que priorizaremos nessa discussão, uma vez que os exemplos que analisaremos posteriormente respondem a essa edição -, encontramos o projeto gráfico-editorial entre os critérios classificatórios de avaliação do LDP. Na primeira menção feita a ele, o Guia traz as características dos "aspectos gráficoeditoriais" que são desejáveis em um material para o ensino-aprendizagem de Língua Portuguesa:

Quanto aos aspectos gráfico-editoriais, um livro dedicado ao ensino-aprendizagem de Língua Portuguesa precisa ser legível e bem ilustrado. Nesse sentido, são importantes: um sumário e uma organização interna que permitam a localização precisa das informações; uma impressão isenta de erros graves, legível e nítida, com

\footnotetext{
${ }^{1}$ Atualmente o Programa é desenvolvido pelo Fundo Nacional de Desenvolvimento da Educação (FNDE) e pela Secretaria de Educação Básica (SEB).
} 
tamanho adequado de letra e espaço entre linhas, entre letras e palavras; uma gramatura de papel que não prejudique a legibilidade. Quanto às ilustrações, devem ser bem distribuídas nas páginas e colaborar para a consecução dos objetivos das atividades a que se relacionam, além de evitar os estereótipos, os preconceitos, a propaganda e a doutrinação ideológica (Brasil, 2007a, p. 17).

Podemos ver que os critérios incluem a organização do material e aspectos bastante técnicos, relativos principalmente à legibilidade. O projeto gráfico-editorial aparece relacionado ao projeto pedagógico apenas na menção às ilustrações, ainda que o Guia não esclareça o que deve ser entendido por "colaborar" com as atividades. Depois dessa menção inicial, os aspectos gráfico-editoriais aparecem novamente nas fichas de avaliação fornecidas anexas ao Guia, a fim de facilitar a escolha do LDP pelos professores nas escolas, nas quais continuam a predominar critérios relacionados à legibilidade, com a diferença de que a referência às ilustrações tendenciosas não aparece mais. Como nos lembra Bocchini, a legibilidade da obra é um elemento importante na sua composição, principalmente quando se trata de um material utilizado para fins didáticos, "o desenho das letras e outros elementos visuais do texto impresso são importantes porque podem facilitar a leitura ou torná-la mais lenta e menos compreensiva" (Bocchini, 2007, p. 2-3).

Porém, o Guia parece privilegiar somente esse aspecto, não mencionando ou referindo-se de maneira vaga a outros elementos do projeto gráfico-editorial. Talvez por esse motivo, a autora argumenta que existe certa displicência com relação às exigências do Programa para os aspectos gráfico-editoriais das coleções, já que "indefinidas e colocadas entre os critérios de qualificação, as condições do projeto gráfico não exigidas, mas apenas esperadas, permitem a aprovação de qualquer modalidade de arranjo visual das páginas dos didáticos" (Bocchini, 2007, p. 9).

No Guia do PNLD/2011, os critérios relativos ao projeto gráfico-editorial passam por algumas alterações e deixam de ser apenas classificatórios, podendo gerar a exclusão das coleções. Nessa edição do Guia, além dos aspectos gráfico-editoriais passarem a ser considerados parte de um projeto, são explicitamente relacionados ao projeto pedagógico. Ainda assim, essa relação não se estende aos critérios, que ainda priorizam a legibilidade do material e aspectos técnicos. Nas ilustrações, o termo genérico com o qual o PNLD refere-se aos elementos visuais do LDP, os critérios deixam de ser negativos, explicitando como elas não devem ser, e passam a ser positivos, no sentido de informar quais devem ser suas características. A ficha de avaliação do PNLD/2011 é bastante parecida com a do Guia de 2008. A organização e a 
impressão ainda são pontos importantes, mas são acrescidas a avaliação dos tipos e da diagramação da página. As ilustrações também passam a ser abordadas e surge o termo “imagens”, que não aparecia nos critérios arrolados.

Podemos dizer que existe uma imprecisão nos critérios e na abordagem dos mesmos na ficha de avaliação, tanto no Guia do PNLD/2008 quanto na edição de 2011. Ao referir-se a "imagens de boa qualidade", por exemplo, o Programa não deixa claro de que forma os professores devem avaliá-las na escolha do LDP. As resenhas dos avaliadores, por sua vez, limitam-se a abordar os aspectos considerados pelos critérios. O projeto gráfico-editorial, de certa forma, passa a ser avaliado muito mais como um componente técnico do LDP do que como um fator determinante para a realização do projeto pedagógico. Quando o projeto gráfico-editorial é associado ao ensinoaprendizagem, mais uma vez, faltam critérios precisos para dar conta da complexidade dessa relação. Essa insuficiência se torna ainda mais relevante quando estabelecemos uma relação com os novos letramentos e as demandas atuais de ensino.

\section{PROJETO GRÁFICO-EDITORIAL E AS NOVAS DEMANDAS PARA A EDUCAÇÃO LINGUÍSTICA}

Nas últimas décadas, com a globalização e as novas tecnologias, a sociedade tem passando por transformações que estão modificando as relações sociais e as formas como as pessoas lidam com o mundo e com a linguagem. Segundo Nogueira (2007, p. 80), os alunos que estão nas escolas hoje pertencem à geração que é conhecida como “"geração (inter)net' (net generation) ou 'geração digital' (digital generation)”. Esses

jovens, que cresceram na era digital, estão acostumados ao dinamismo e à abundância de informações disponíveis na internet, nos celulares, até mesmo nos videogames, entre outras mídias. Ao mesmo tempo, "autores como Roland Barthes enfatizam que a nossa época é a da relação texto/imagem" (Cavalcante, 2008, p. 55), imagens essas que "possuem cada vez mais espaço no mundo diante de tantos avanços tecnológicos, principalmente no que se refere ao universo imagético" (Cavalcante, 2008, p. 55).

De acordo com Rojo (2009), as novas configurações da sociedade têm tido impacto direto nos letramentos e, por isso, devem ser encaradas de maneira crítica pela escola. As quatro principais mudanças elencadas pela autora são: i) "a vertiginosa intensificação e a diversificação da circulação da informação nos meios de comunicação analógicos e digitais" (Rojo, 2009, p. 105), que têm colocado em xeque o 
impresso e o papel; ii) "a diminuição das distâncias espaciais" (Rojo, 2009, p. 105), que tem efeitos sobre a construção das identidades e o enraizamento das populações; iii) "a diminuição das distâncias temporais ou a contração do tempo" (Rojo, 2009, p. 105), que têm tornado o instantâneo e o imediato as medidas que regem o cotidiano; iv) "a multissemiose ou a multiplicidade de modos de significar que as possibilidades multimidiáticas e hipermidiáticas do texto eletrônico trazem para o ato da leitura" (Rojo, 2009, p. 105), que tem tornado o texto verbal escrito insuficiente diante das possibilidades de associação a signos de outras modalidades.

Ainda segundo a autora, no contexto dessas mudanças está uma cultura de massa, fruto da globalização e da sociedade de consumo, que é

\begin{abstract}
padronizada, monofônica, homogênea e pasteurizada [...] Por isso, se tornam tão importantes hoje as maneiras de incrementar, na escola e fora dela, os letramentos críticos, capazes de lidar com os textos e discursos naturalizados, neutralizados, de maneira a perceber seus valores, suas intenções, suas estratégias, seus efeitos de sentido (Rojo, 2009, p. 112).
\end{abstract}

O papel da escola, hoje, é possibilitar que seus alunos sejam letrados para "participar de várias práticas sociais que se utilizam da leitura e da escrita (letramentos) na vida da cidade, de maneira ética, crítica e democrática” (Rojo, 2009, p. 107). Faz-se necessário, então, responder com novas estratégias a esses impactos "que têm transformado o letramento tradicional (da letra/livro) em um tipo de letramento insuficiente para dar conta dos letramentos necessários para agir na vida contemporânea" (Rojo, 2009, p. 107).

(...) tendo em vista o papel do discurso nas sociedades densamente semiotizadas em que vivemos (...) ensinar a usar e a entender como a linguagem funciona no mundo atual é tarefa crucial da escola na construção da cidadania (Moita-Lopes \& Rojo, 2004, p. 46, citado por Rojo, 2009, p. 89).

Diante dessas novas demandas, vemos que algumas práticas ainda permanecem, e o uso do LDP como instrumento central no ensino-aprendizagem de Língua Portuguesa é uma delas. Ainda que, gradualmente, esse não seja o único material presente nas salas de aula, encontrando apoio em CD-ROMs, sites e outras plataformas a serem desenvolvidas, atualmente estamos diante do desafio de letrar através do impresso para uma realidade que é dinâmica, digital, multimodal e plural. Entendemos que, diante desse impasse, é insuficiente um LDP que lida com as imagens, ilustrações e 
diferentes textos e suportes de maneira acrítica. O projeto gráfico-editorial do LDP, nesse sentido, deveria corresponder à complexidade das interfaces encontradas na internet, das relações entre os textos verbais e as imagens, as cores, o movimento, das novas formas de ler e organizar a linguagem, que carregam ideologias e valores, com os quais o alunado precisa aprender a lidar de maneira mais crítica e consciente. A realidade encontrada nos LDP, porém, é outra e, como estamos tentando mostrar neste artigo, o projeto gráfico-editorial tem seu papel nesse descompasso. A fim de ilustrar as reflexões feitas até aqui, trazemos dois exemplos de atividades de leitura de um LDP cujo projeto gráfico-editorial inadequado mostrou-se claramente desfavorável ao seu projeto pedagógico. Antes, traçamos um breve perfil da coleção, a fim de ressaltar essas incongruências.

\section{EXEMPLIFICANDO A DISCUSSÃO}

Os exemplos que utilizaremos para ilustrar a discussão feita até aqui são da coleção "Leitura do Mundo", editada pela Editora do Brasil e publicada pela primeira vez em 1999, de autoria de uma mestre e de uma doutora em Linguística e Semiótica pela Universidade de São Paulo. O critério para seleção dessa coleção foi seu parecer quanto ao projeto gráfico-editorial no Guia do PNLD/2008. "Leitura do Mundo" recebeu uma avaliação negativa no quesito, o que tomamos como indício para a análise. Neste artigo, analisamos um exemplo do volume destinado ao $6^{\circ}$ e um do $7^{\circ}$ ano da $3^{\mathrm{a}}$ edição da coleção. Em aspectos gerais, cada volume é organizado em 9 unidades temáticas, com as seções "Texto", "Leitura do texto", "Leitura do mundo", "Gramática", "Hora de falar" e "Hora de escrever". O volume do $6^{\circ}$ ano possui 43 textos e 86 imagens, distribuídos em 168 páginas e o padrão se repete no exemplar do $7^{\circ}$ ano, com 49 textos e, novamente, 86 imagens, em 200 páginas. A média que se estabelece é de, aproximadamente, 1 texto a cada quatro páginas e 1 imagem a cada duas páginas.

Visualmente, há um predomínio da mancha de texto. Há somente um tipo padrão, serifado, estilo Times New Roman, corpo 11, impresso em preto, utilizado no texto autoral, texto da coletânea e exercícios, o que confere à coleção um menor grau de legibilidade e uma sensação de "empastelamento". Para diferenciação de títulos e subtítulos, empregam-se os recursos de caixa alta, sombra, negrito e variação da cor do 
tipo padrão. As exceções ficam por conta do uso de um tipo fantasia ${ }^{2}$ nos títulos que antecedem os textos da coletânea e de um tipo serifado diferente do padrão no início de cada unidade. Os boxes e quadros aparecem em pouca quantidade e suas inserções são marcadas pela alteração da cor de fundo e por uma linha delimitando essa mancha específica de texto.

No PNLD/2008, de forma geral, a coleção é bem avaliada:

Pela cuidadosa análise de textos verbais e não-verbais e pela qualidade de sua coletânea, esta coleção pode contribuir para a formação estética e cultural dos jovens. As propostas de escrita, em geral, consideram o gênero e o tipo, os objetivos e interlocutores do texto e alertam quanto às etapas do processo de produção. $\mathrm{O}$ trabalho com oralidade oferece menos subsídios aos alunos. No estudo linguístico, a obra, de um lado, focaliza recursos textuais e discursivos; de outro, contempla conteúdos gramaticais tradicionais. $\mathrm{Na}$ análise dos textos e nos estudos gramaticais, predomina a tendência de oferecer aos alunos orientação minuciosa. Esse tratamento didático dos conteúdos, bastante diretivo, deixa pouco espaço para reflexão e construção. (Brasil, 2007b, p. 57, grifo nosso)

No Quadro Esquemático da avaliação, também é destacada a pertinência da coleção para a formação cultural e estética do alunado e a coletânea é considerada relevante:

A coletânea traz tipos e gêneros variados da cultura da escrita (nas esferas jornalística, científica, publicitária e literária) e das linguagens visuais. Oferece produções artísticas diferenciadas (literatura, pintura, escultura, desenho, fotografia) e produtos de comunicação de massa, como jornal, revista, quadrinhos e infografia (gêneros jornalísticos que se valem de recursos gráfico-visuais para apresentação sucinta das informações). (Brasil, 2007b, p. 58).

A resenha do Guia, de certa forma, corresponde às expectativas das autoras sobre a coleção, como podemos ver no excerto da apresentação que elas assinam, localizada no início de cada volume. Segundo elas, o livro "é realmente uma Leitura do mundo, pois reunimos aqui poesias, histórias, pinturas, propagandas, quadrinhos, vários tipos de texto que mostram e constroem o mundo em que vivemos" (Discini \& Teixeira, 2006, p. 3).

A ressalva dos avaliadores à coleção fica por conta do projeto gráfico-editorial, principalmente no que toca à legibilidade:

\footnotetext{
2 Os tipos fantasia, ou decorativos, são todos aqueles que não obedecem às características das 4 categorias básicas da tipografia: tipos serifados, sem serifa, manuscritos ou de tamanho fixo. Os tipos fantasia apresentam grande variedade de padrões e podem conter elementos ilustrativos em seus traços, sendo mais utilizados em títulos e logotipos.
} 
O projeto editorial tem a inadequação de apresentar páginas carregadas com textos e atividades, com letras muito miúdas. O sumário é relativamente funcional, facilitando a localização de unidades e seções. Os textos vêm arrolados por número e não pelo título (ex.: Texto 1, Texto 2), o que impossibilita sua identificação. (Brasil, 2007b, p. 60)

Uma vez que vamos analisar exemplos de atividades de leitura, podemos ilustrar o perfil dos textos no projeto gráfico-editorial de Leitura do Mundo. Em um total de 43 textos, a maior parte (41) possui direitos autorais. Esse dado é positivo, na medida em que mostra a prioridade dada a textos autênticos, que não foram produzidos pelos autores do LDP especificamente para ele, mas circularam antes em contextos nãoescolares. Mais da metade (26) aparece na versão integral, sem edição, o que significa, por um lado, custos maiores em direitos autorais e, por outro, a predileção por gêneros de menor extensão, como o poema ou a crônica, que podem ser reproduzidos sem ocupar muito espaço no material. De fato, constatamos que $30 \%$ da coletânea é constituída por poemas, um gênero sempre presente nas obras didáticas, justamente pelos motivos que acabamos de citar. 55\% dos textos em Leitura do Mundo são acompanhados por imagens. Verificamos, porém, que grande parte delas é redundante e tem função meramente decorativa. Os dados mais significativos na análise da coleção foram a presença ínfima de textos multimodais (5) e a ausência de textos reproduzidos com a mesma configuração do suporte original, fac-similados.

Tendo em vista esse perfil, passemos agora aos nossos exemplos.

\section{Análise de um exemplo de texto no volume do $6^{\circ}$ ano}

O primeiro exemplo está nas páginas 116 e 117 (cf. Anexo 1) do volume do $6^{\circ}$ ano de Leitura do Mundo, que fazem parte da unidade 7, cujo tema é "Trabalho".Nessas páginas, temos duas atividades de leitura. A primeira, na seção "Leitura do Mundo", analisa uma pequena história a respeito de Cândido Portinari. Depois, sob o título “Texto 2", temos uma reportagem veiculada no site do O Globo, sobre a qual são feitas algumas perguntas na seção "Leitura do Texto 2". Podemos perceber que a reportagem foi readequada ao projeto gráfico do LDP, utilizando seus tipo e corpo padrões. Na figura, ela ocupa a metade inferior da página à esquerda e a metade superior da página à direita, sem a delimitação de nenhum quadro ou borda. As únicas referências à fonte e autoria aparecem ao final do texto, no link do site em que a reportagem foi veiculada inicialmente. Quanto à imagem que a acompanha, o projeto gráfico-editorial não deixa 
claro se integrava a reportagem no veículo original. Porém, uma simples leitura do texto nos permite afirmar com certeza que não. Com o título "Pobreza obriga menores a entrarem precocemente no mercado de trabalho", a reportagem aborda a realidade de três jovens moradores de favelas do Rio de Janeiro, que desde cedo se viram obrigados a trabalhar para colaborar com o orçamento precário de suas famílias. A fotografia, no entanto, retrata uma cena típica de exploração do trabalho infantil, mostrando um garoto realizando a colheita de cana, em um ambiente rural. Temos na imagem, portanto, uma temática distinta da trabalhada na reportagem. Considerando que nos textos jornalísticos autênticos as imagens podem colaborar com a construção do sentido, ativando conhecimentos e preparando a leitura, no exemplo a fotografia acaba gerando falsas expectativas sobre o tema que vai ser tratado na reportagem. Uma explicação possível para essa discrepância seria a de que os responsáveis pelo projeto gráfico-editorial, sejam eles o pesquisador de iconografia, o diagramador ou mesmo o editor, não fizeram a leitura do texto para selecionar a imagem que o acompanharia, pautando-se, provavelmente, apenas nas expressões do título, como "pobreza", "menores", "mercado de trabalho", que realmente poderiam referir-se à temática do trabalho infantil. Nesse exemplo, ao esvaziar as relações existentes entre texto e imagem na reportagem, o equívoco no projeto gráfico-editorial pode impedir que os alunos tomem contato apropriado com esse gênero.

\section{Análise de um exemplo de texto no volume do $7^{\circ}$ ano}

Charges, histórias em quadrinhos, infográficos, mapas cartográficos, anúncios publicitários e notícias jornalísticas acompanhadas de imagens são exemplos de gêneros em que imagem e texto se complementam, a fim de estabelecer uma unidade de sentido. No exemplo que trazemos, porém, percebemos que, mesmo nesses gêneros, o projeto gráfico-editorial pode prejudicar essa significação mais complexa. Na reprodução da página 190 (cf. Anexo 2) do volume do $7^{\circ}$ ano de Leitura do Mundo, parte da unidade 9 , que tem como tema a Publicidade, temos um anúncio do produto Vaporella, identificado como "Texto 3 - Propaganda", a partir do qual são feitas várias questões.

Ao compararmos a reprodução no veículo de circulação original ${ }^{3}$ (cf. Anexo 3), percebemos que o anúncio, originalmente publicado em página dupla, foi reconfigurado

\footnotetext{
3 O anúncio original foi obtido no Acervo Digital da revista Veja, que pode ser acessado em http://veja.abril.com.br/acervodigital/home.aspx.
} 
para ocupar cerca de um sexto deste espaço, menos da metade da página do LDP. Acreditamos que esse limite de espaço tenha levado à substituição dos tipos originais pelo tipo padrão usado em todo o LDP, em corpo menor, mas que garante a legibilidade do texto. Ainda que essa seja uma alteração justificável, houve comprometimento da constituição do texto no gênero e, consequentemente, de sua apropriação pelos alunos. No anúncio do LDP não foi respeitada a disposição original do conteúdo e a diferenciação entre os tipos que constituem o texto de apoio e as legendas explicativas do produto. O logo do "Serviço de Atendimento ao Cliente" ganhou mais destaque que a marca e o nome do produto, enquanto que a referência à agência de publicidade responsável pela criação, originalmente localizada no canto superior esquerdo, simplesmente foi suprimida.

Essas ações, ao apagar elementos importantes do contexto de produção e circulação do anúncio, acabaram por transformá-lo, de texto multimodal, em mais um texto verbal acompanhado de ilustração, impossibilitando que os alunos apropriem-no como um texto autêntico, com suas estratégias de leitura e interpretação específicas preservadas. Além disso, elas parecem não condizer com as opções pedagógicas das autoras. No manual do professor, referindo-se à coletânea, elas afirmam:

Levamos em conta, para a variedade da seleção, não só que o livro didático é um instrumento privilegiado de acesso do aluno ao mundo dos textos escritos, mas também um dos primeiros veículos a oferecer-lhe a possibilidade de aprender a ler a visualidade. (Discini \& Teixeira, 2006, p. 8).

Como vimos, a apropriação da coletânea pelo projeto gráfico-editorial não favoreceu essa leitura mais sofisticada, ignorando as especificidades do gênero publicitário.

\section{CONSIDERAÇÕES FINAIS}

Neste artigo, buscamos definir e problematizar o projeto gráfico-editorial do LDP de Língua Portuguesa na perspectiva da Linguística Aplicada. A nosso ver, esse objeto de estudo mostra-se bastante relevante em uma realidade em que o LDP se coloca ao mesmo tempo como produto comercial e material de ensino-aprendizagem, num conflito que traz à tona as disputas entre os campos autoral e editorial, fazendo com que muitas vezes ações na edição e diagramação do livro, sob responsabilidade do 
editor, interfiram na proposta pedagógica do autor, ora comprimindo-a numa configuração visual não condizente com os objetivos de ensino-aprendizagem, ora contribuindo para o aproveitamento do material por alunos e professores. Ao analisar dois exemplos de atividades de leitura de uma coleção de livros didáticos que teve seu projeto gráfico-editorial considerado inadequado procuramos mostrar como esses aspectos podem se relacionar ao projeto pedagógico, às vezes negativamente.

A coleção "Leitura do Mundo", como pudemos expor, apresentou características que não consideramos positivas para seu aproveitamento na sala de aula. Contrariando o parecer dos avaliadores, a coletânea da coleção mostrou-se pouco diversificada, fato agravado pela forma como foi inserida nos LDP. Não foram respeitadas, na maior parte das vezes, as características de imagens e textos, desconfigurados ou redesenhados para atenderem limites de espaço ou economia de custos em direitos autorais, por exemplo. A nosso ver, mais do que desestimular a leitura e ser pouco atrativo, o projeto gráficoeditorial de "Leitura do Mundo" ao se valer de textos e imagens com contextos de produção e circulação apagados, pouca diversidade nas referências, não contribui para os múltiplos letramentos exigidos em nossa sociedade, que pede novas formas de ler, interpretar e relacionar textos, imagens e informações de forma dinâmica e ativa, nas mais diferentes mídias (Rojo et al., s/d). Acreditamos que essa configuração dá indícios de que o processo de escrita do livro e sua edição e diagramação aconteceram de forma independente, sem permitir um trabalho colaborativo entre autores e editores.

Consideramos que o projeto gráfico-editorial ainda não é devidamente entendido e explorado por autores, editores e avaliadores, uma situação que se torna problemática, pois incompatível com uma realidade que não exige somente a leitura de textos escritos, mas letramentos multissemióticos, que abrangem as imagens, os sons, as cores, os movimentos, cada vez mais acessíveis através da tecnologia. Visto que é da escola grande parte da responsabilidade na apropriação dos letramentos múltiplos, multimodais e críticos por seu alunado, o LDP, como material fundamental para o ensinoaprendizagem nesses locais, deve estar alinhado a esses objetivos. Infelizmente, porém, as novas demandas do ensino de Língua Portuguesa na sociedade contemporânea parecem ainda estar pouco presentes nos critérios do PNLD para o projeto gráficoeditorial.

No caso de "Leitura do Mundo", por exemplo, ao elogiar a coletânea de uma obra que conta com um projeto gráfico-editorial inadequado, os avaliadores revelam ter pouca dimensão da importância dos aspectos gráficos na consecução do projeto 
pedagógico, principalmente quando consideramos o LDP um gênero secundário do discurso que, como tal, tem em sua forma composicional um componente essencial para sua realização.

Acreditamos que o PNLD, que desde seu surgimento teve o objetivo de regular e forçar melhorias na produção dos $\mathrm{LD}$, ainda apresenta critérios insuficientes para a definição do projeto gráfico-editorial das obras. No espaço limitado deste artigo, procuramos pistas que pudessem nos auxiliar a pensar o que seria um bom projeto gráfico-editorial para o ensino-aprendizagem de Língua Portuguesa atualmente, procurando trazer à tona um tema relevante e ainda pouco pesquisado, contribuindo para que ele adquira a merecida importância nos estudos sobre o LDP, já que mais do que nos contentarmos com livros legíveis e bem ilustrados, hoje devemos pensar em livros que sejam tão desafiadores, dinâmicos e fascinantes quanto são os nossos tempos.

\section{REFERÊNCIAS}

Alves Filho, F. (2006). A autoria institucional nos editoriais de jornais. Alfa: Revista Linguística, 5 (1), 77-89.

Bakhtin, M. (2003/1952-53/1979). Os gêneros do discurso. In: Estética da Criação Verbal, $4^{\mathrm{a}}$ ed. São Paulo: Martins Fontes.

ed. São Paulo: Hucitec.

/Volochínov, V. N. (1981/1929). Marxismo e filosofia da linguagem. $2^{\text {a }}$

Batista, A. A. G.; Rojo, R. H. R.; Zuñiga, N. (2005). Produzindo livros didáticos em tempo de mudança. In: M. G. Costa Val \& B. Marcuschi (orgs.) Livros didáticos de Língua Portuguesa: letramento e cidadania. Belo Horizonte: Autêntica/CEALE.

Bocchini, M. O. (2007). Legibilidade visual e projeto gráfico na avaliação de livros didáticos pelo PNLD. In: Anais do Simpósio Internacional Livro Didático: Educação e História. São Paulo: EDUS. Disponível em: <http://www.abrale.com.br/biblioteca/Maria_Otilia_Bocchini.pdf $>$. Acesso em: 16 ago. 2009.

Bragança, A. (2005) Sobre o editor: notas para sua história. Em Questão, 11 (2), 219 237.

Brasil, Ministério da Educação. (2007a). Edital de Convocação para Inscrição no Processo de Avaliação e Seleção de Obras Didáticas a Serem Incluídas No Guia De Livros Didáticos para os Anos Finais do Ensino Fundamental - PNLD/2008. MEC/FNDE. 
Brasília: MEC/FNDE.

(2007b). Guia de livros didáticos PNLD/2008: Língua Portuguesa.

Cavalcante, N. S. (2008). Linguagem das figuras, figuras de linguagem ou conversando sobre ilustração. In: J. L Farbiarz, A.Farbiarz \& A. L. Coelho (orgs.) Os lugares do design na leitura. Rio de Janeiro: Editora Novas Ideias.

Chartier, R. (1999/1945). A aventura do livro: do leitor ao navegador. Tradução de Reginaldo de Moraes. São Paulo: Editora UNESP/Imprensa Oficial do Estado de São Paulo.

(2001/1985). (Org.) Práticas da Leitura. Tradução de Cristiane Nascimento. $2^{a}$ ed. São Paulo: Estação Liberdade.

Choppin, A. (2004). História dos livros e das edições didáticas: sobre o estado da arte. Revista Educação e Pesquisa [online], 30 (3), 549-566. Disponível em: <http://www.scielo.br/pdf/ep/v30n3/a12v30n3.pdf>. Acesso em: 15 jul. 2009.

Collaro, A. C. (1987). Projeto gráfico: teoria e prática da diagramação. São Paulo: Summus.

Discini, N. \& Teixeira, L. (2006). Leitura do Mundo. $3^{\text {a }}$ ed. São Paulo: Editora do Brasil.

Faraco, C. A. (2005). Autor e autoria. In: B. Brait (org.) Bakhtin: conceitos-chave. São Paulo: Contexto.

Moraes, D. D. C. D. (2010). Visualidade do livro didático no Brasil: o design de capas e sua renovação nas décadas de 1970 e 1980. Dissertação de mestrado inédita. Faculdade de Educação da Universidade de São Paulo.

Pivetti, M. (2005). O diálogo gráfico/editorial: projeto gráfico e hipóteses de trabalho. In: Anais do Congresso Brasileiro de Ciências da Comunicação, 28. São Paulo: Intercom, $2005 . \quad$ Disponível em: <http://www.intercom.org.br/papers/nacionais/2005/resumos/R1676-1.pdf>. Acesso em: 25 jul. 2009.

Rojo, R. (2009). Letramento(s) - práticas de letramento em diferentes contextos. In: Editorial. Letramentos múltiplos, escola e inclusão social. São Paulo: Parábola

\& Bunzen, C. (2005). Livro didático de Língua Portuguesa como gênero do discurso: autoria e estilo. In: M. G Costa-Val \& B. Marcuschi (orgs.) Livros didáticos de Língua Portuguesa: letramento e cidadania. $1^{\mathrm{a}}$ ed. Belo Horizonte: Autêntica.

Tenan et al. (2008). Caracterização do Processo de Edição de Textos Didáticos Colaborativos: o Caso Wikibooks. In: Anais do XXXI Congresso Brasileiro de Ciências da Comunicação. Natal: Intercom. 


\section{A AUTORA}

Fabiana Panhosi Marsaro é licenciada em Letras pela Universidade Estadual de Campinas e mestranda em Linguística Aplicada pela mesma instituição. Desenvolve pesquisa sobre o livro didático em língua materna, tendo particular interesse nos temas: aspectos gráfico-editoriais, relação editor-autor, letramentos e multimodalidade.

E-mail: fabiana.marsaro@gmail.com 


\section{ANEXO 1}

\section{LEITURA DO MUNDO}

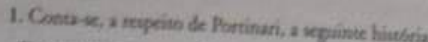

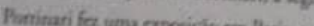

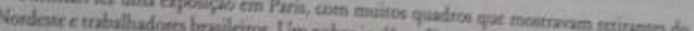

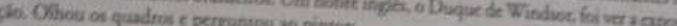

- Mas o sentur nlo pinta flone? a pintor:

E Porrinari moponders

- Nia, meu senhore $5 \delta$ pinto mistria.

Eisu hivtíria mostra:

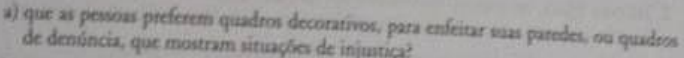

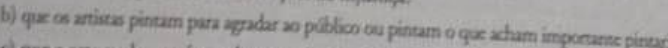

c) goe a arte pode agradar a a lgamas penvosi e deagradar a outras

d) que a arte de Portinari t uma arte com motivos predominamemente popelatea, de

corativos, braileitos, mundiais, leves, sociais. Quais dene?

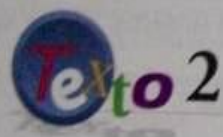

POBREZA OBRIGA MENORES A ENTRAREM

PRECOCEMENTE NO MERCADO DE TRABALHO

Osonho de Scaginho t juntar o dinheimo conscguido wom

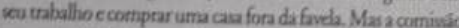
semanal de RSS - quando consogue vender alguns diinelor numa pequena loja no complexs do Alemáo - está atrasundo a talmaplo do seu sonha Com apcres 13 anos, Stregio Luiz Gomes do Rosínio engrosea as fileciras dos 45 mithöer de bravilaimos entre 5 e 14 anos qque entraram prococemente no mercada de trathalho. Serginho nio pira. No tempo que sobra, de paricipa de um grupo musical, com outros der adolescentes, na cpxcrança de um setomo financciro mais tápido. A infincia de brincadeiras euti diantante. No Complexo do Alemia, de it passou por maus pedacos: levou tapas de policiais durante uma blitz, controu pasa fiugir de bala pertida e perdeu amigos que se envelveram com as drogas.

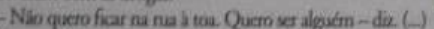

Ramon Pondriguea de Souma, de 14 anos, que há trés anos

integra o conjunto Alucinantes, 20 lado de Serginho, mora em um cómodo com a míc c doí irmains, numa favela em Anchieta. Ele acredita que o dinheito que ganhari como cantor veri suficiente pasa comprar uma casa. Por enquanto, as appesentaçóe do grupo sáo gratritas.
- Eu dou para minha mie ir juntando. Ela sabe que naio vou cair nessa de roubat, matar, ficat plantado - afirma. (...)

O grupo ía gravou um CD e busca patrocinador. A cantora principal, Lucilene Bragança Assis, de 14 anos, ji trabalhou como secretiria, mas acredita que a cartcira arristica ét destino

- Ê uma oportunidade que náo vou despendiçat

Em busca de novas oportunidades, esses menotes procuram também cursos profission lizantes. Só na Favela de Viginio Geral, a Casa da Paz tem cerca de 800 jovens cm cursos de alfabetizaçio, davilografia, ille-seren, informisa da Paz tem cerca de 800 jovens em cursos de

Daniel Rodrigues Lucena, de 15 anos, é a revela ̧äo do curso de grafiec. Abandonou a pichaço e sonha contribuir para o orgamento familiar usando o dinheiro de sua nova profissio.

(Angrtina Nunes, http://wwwoglobo,com.br/arquivo/rio/19971102/rio30.htm)

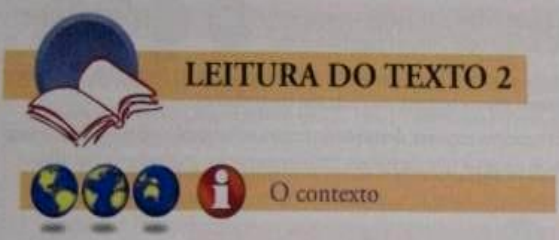

1. Complexo do Alemáo é um conjunto de favelas na Zona Norte da cidade do Rio de Janciro. a) Quais foram os "maus pedaços" por que Serginho já passou na favela?

b) Ramon, o amigo de Serginho, disse, sobre sua măe: "Ela sabe que náo vou cait ness de roubar, matar, ficar plantado".

"Ficar plantado" é uma gíria, um modo de falar próprio de um grupo. Significa ficar envolvido com o trífico de drogas, o negócio de venda de drogas.

Juntando o que Serginho já passou, com o que Ramon disse, fale sobre o tipo de problemas enfrentados pelos meninos nas favelas em que viviam.

c) Como Serginho e Ramon tentam escapar desses problenas?

2. a) Autoconfianna significa a confiança que alguém tem em si mesmo. Auto-imagem significa a imagem que alguém tem de si mesmo. A Casa da Paz, alèm dos cursos ministrados, ajuda na construḉo da autoconfiança e da auto-imagem dos jovens da Favela de Vigánio Geral? Por quê?

- Noticia sobre a Casa da Paz

A Casa da Pan ma fivela de Vigirio Geral, foi criada algum tempo depois de uma grande violencia aconrecid na favela. Fm 1993, 21 pessoas foram assassinadas. Esse episódio ficou conhecido como a "chacina de Vigário Geral", e onze policiais militares foram acusados do crime. Alguns jả foram condenados pela justiça.

b) Filk-screen c grafite sảo cursos pouco comuns. Silk-screen é a técnica que ensina a imprimir, por exemplo, figuras $\mathrm{cm}$ camisetas. Grafites sio pichaçōes feitas nos mutos. nas paredes, mas são também desenhos artisticos, em grandes painéis.

Oferecendo cursos profissionalizantes pouco comuns, a Casa da Paz mostra competência, sabedoria para atrair os jovens. Por quê?

Como a Casa da Paz transforma pichadores de rua em trabalhadores?

Exemplo de texto em Leitura do Mundo $6^{\circ}$ Ano (DISCINI; TEIXEIRA, 2006, p. 116-117) 


\section{ANEXO 2}
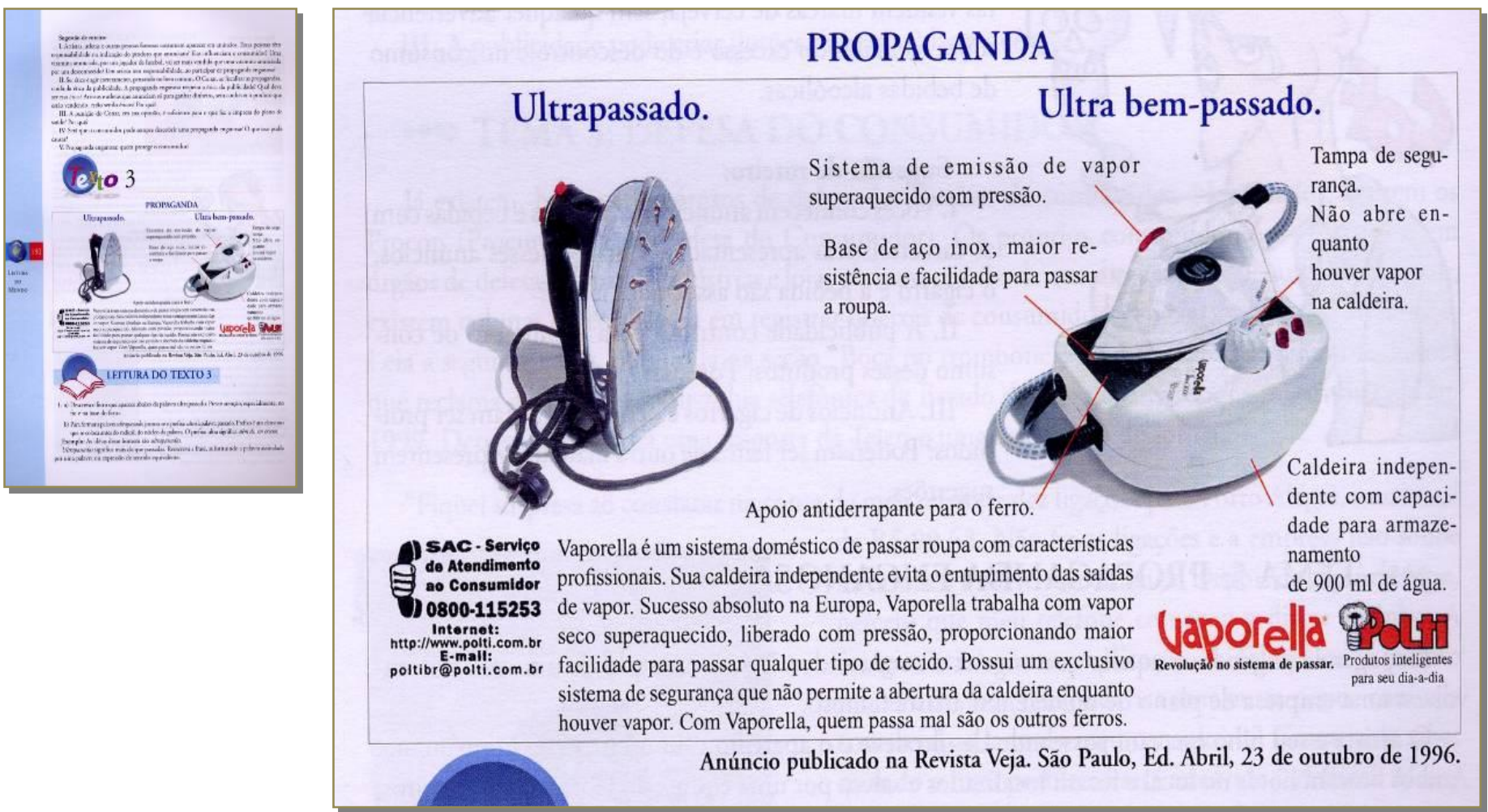

Exemplo de texto em Leitura do Mundo $7^{\circ}$ Ano (DISCINI; TEIXEIRA, 2006, p. 190) 


\section{ANEXO 3}

\&

Ultrapassado.

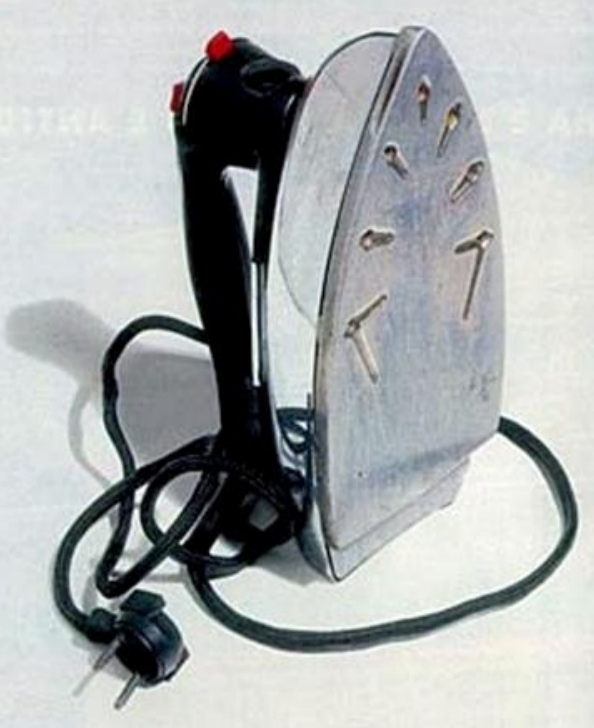

A sace. Semke

Vaporetla 6 um sistema dombstico do passar roupa com caracteristicas profissionais. entupimento das saidas de vapoc Sucesso absoluto na Europa, Vaporella trabalha con com pressbo, proporcionando maior facildade pava passar quilquer bpo de lecido. Possu que nsto permile a abertura da caldeira enquanto houver vapoe Com Vaporella, quem

\section{Ultra bem-passado.}

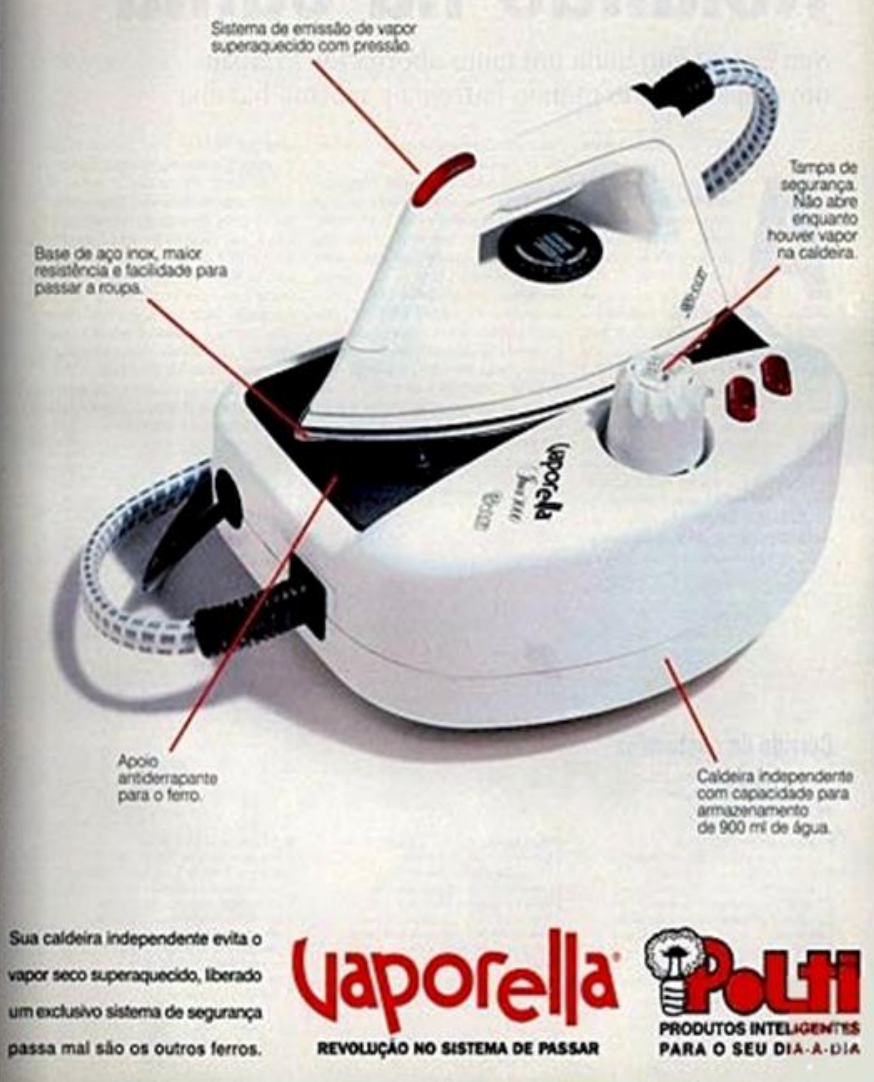

Anúncio original disponível no Acervo Digital da revista Veja 